\title{
GREAT HORNED OWL REMOVES PURPLE MARTIN FROM BIRDHOUSE
}

KERRY HECKER, LOWELL STRAUSS Email: kerry.hecker@gmail.com

On 18 May 2013 at 21:25 h, just at dusk (sunset was at 20:50 h), we saw our resident Great Horned Owl (Bubo virginianus) clinging with its talons to the side of the Purple Martin (Progne subis) house, flapping to keep its balance. It then flew down to the ground, $10 \mathrm{~m}$ away. Two or three minutes later we observed it (with binoculars) flying away with something black in its talons. The thing in its talons was the right size and shape to be a Purple Martin. We've never seen active predation by anything at the Purple Martin house before! We would be interested to know if anyone else

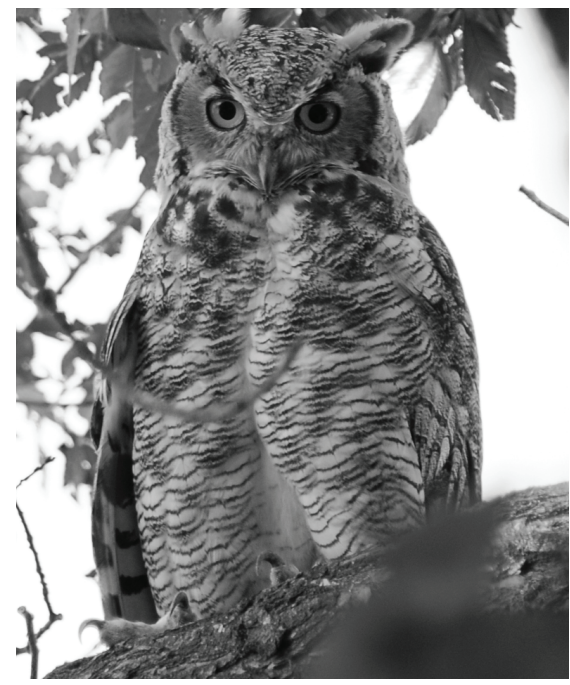
has seen something like this occur.

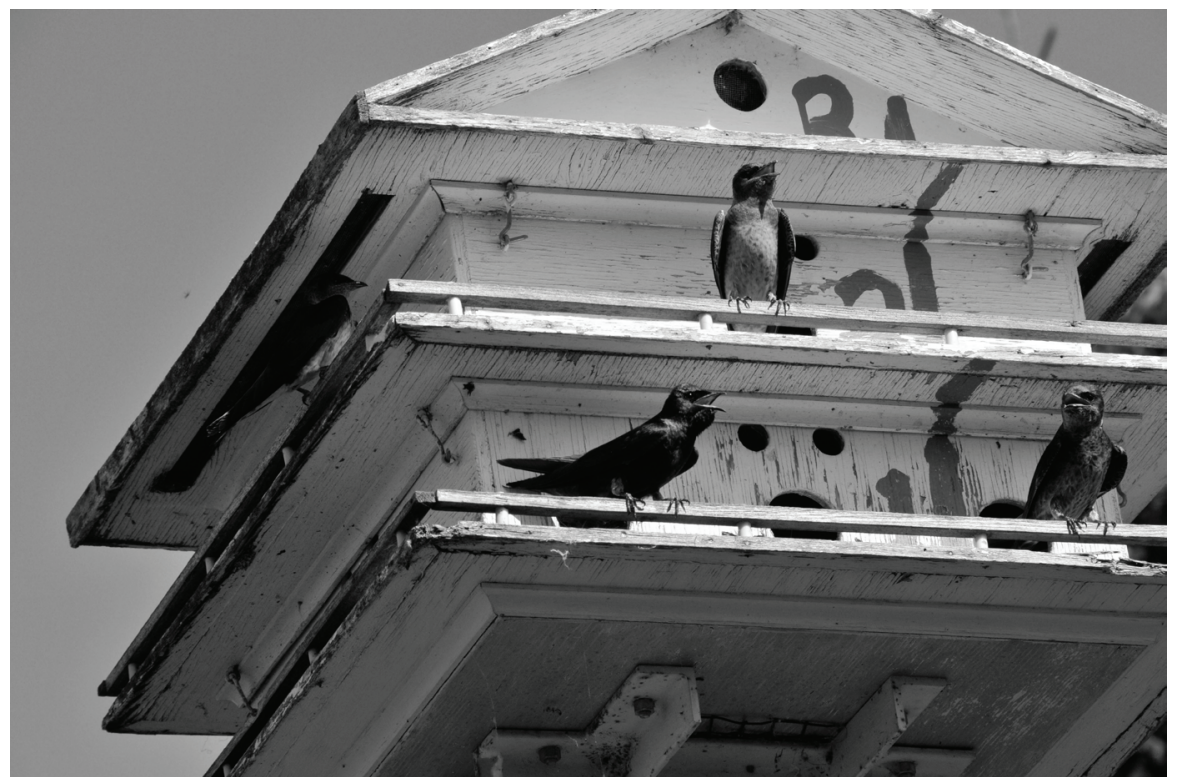

Top: Great Horned Owl lurking in the shadows of a nearby tree.

Bottom: Purple Martin at birdhouse.

-Lowell Strauss

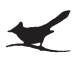

